International Journal of Advanced Studies in Humanities and Social Science (IJASHSS)

Available online at http://www.ijashss.com

Volume 8, Issue 1 (2019) pp. 79-90

Original Article

\title{
Public Park
}

\section{Farzad Zarbakhsh'1, Jafar Yousefpour², Younes Karimpour Hayedi ,} Farhad Yadegari ${ }^{3}$

\author{
${ }^{1}$ Phd Student Hajat Tape, Ankara, Turkey \\ ${ }^{2}$ Professor of Islamic Azad University Khalkhal Branch, Khalkhal, Iran \\ ${ }^{3}$ M. A. Student, Department of Architecture, Islamic Azad University Khalkhal Branch, \\ Khalkhal, Iran
}

Received: 24 October 2018, Revised: 05 December 2018, Accepted: 20 December 2018

\begin{abstract}
How can one expect a rational growth and development of urban communities without a definite guide line for applying fixed elements on city planning such as Park? Introduction: City Planning; the unified development of cities and their environments. For most of its history, city planning dealt primarily with the regulation of land use and the physical arrangement of city structures, as guided by architectural, engineering, and land-development criteria. In the mid-1920th century it broadened to include the comprehensive guidance of the physical, economic, and social environment of a community. Elements characteristic of city planning include (1) General plans that summarize the objectives of land development; (2) Zoning and subdivision controls that specify permissible land uses, densities, and requirements for streets, utility services, and other improvements;(3) Plans for traffic flow and public transportation; (4) Strategies for economic revitalization of depressed urban and rural areas; (5) Strategies for supportive action to help disadvantaged social groups; and (6) Guidelines for environmental protection and preservation of scarce resources. City planning is conducted by governments on all levels-local, county, regional, state, and federal-and by private groups. It is also a subject of university-level study and Professional societies.
\end{abstract}

Keywords: Public Park, Urban Planning, Urban Communities, City Development.

\section{Introduction}

City planning in the west and other countries broadened in the late 1960s beyond a purely physical orientation. In its modern form, city planning is an ongoing process that concerns not only physical design but also social, economic, and political policy issues. As a fabric of human organization, a city is a complex weave. On one level it consists of the arrangement of neighborhoods, industry, and commerce according to aesthetic and functional standards and the provision of public services for them. On another, perhaps more important, level it also comprises:

(1) The background, education, work, and aspirations of its residents;

(2) The general functioning of the economic system to which they belong, as well as their positions in and rewards from that system; and

(3) Their ability to make or influence the policy decisions that affect their daily lives. 
Problem: Viewed from this perspective, city planning requires more than a narrow specialist who can develop and implement a physical plan. More general skills and activities are also needed. They include

(1) The collection and analysis of data about the city and its population;

(2) Research into the need for and availability of social services;

(3) The development, evaluation, coordination, and administration of programs and timetables to supply these services;

(4) programs for economic and housing development and redevelopment-not only planning, but also packaging, financing, and carrying out the development, establishing public and private partnerships, and so forth; and (5) effective use of political activity and citizen participation to influence the character of and give support to development programs.

In this article, we wish to review significance of parks zoning and subdivision controls that specify permissible land uses, densities, and requirements for streets, utility services, and other improvements.
Large area of ground set aside for recreation. The earliest parks were those of the Persian kings, who dedicated many square miles to the sport of hunting; by natural progression such reserves became artificially shaped by the creation of riding paths and shelters until the decorative possibilities became an inherent part of their character. A second type of park derived from such open-air public meeting places as those in ancient Athens, where the functions of an exercising ground, a social concourse, and an athletes' training ground were combined with elements of a sculpture gallery and religious center. In the parks of post-Renaissance times, there were extensive woods, rectilinear allées stretching between one vantage point and another, raised galleries, and, in many cases, elaborate aviaries and cages for wild beasts, attesting to the hunting proclivities of the lords. Later the concept of the public park was somewhat domesticated. An area devoted simply to green landscape, a salubrious and attractive breathing space as a relief from the densely populated and industrialized city of the mid-19th century, became important.

\section{Literature}

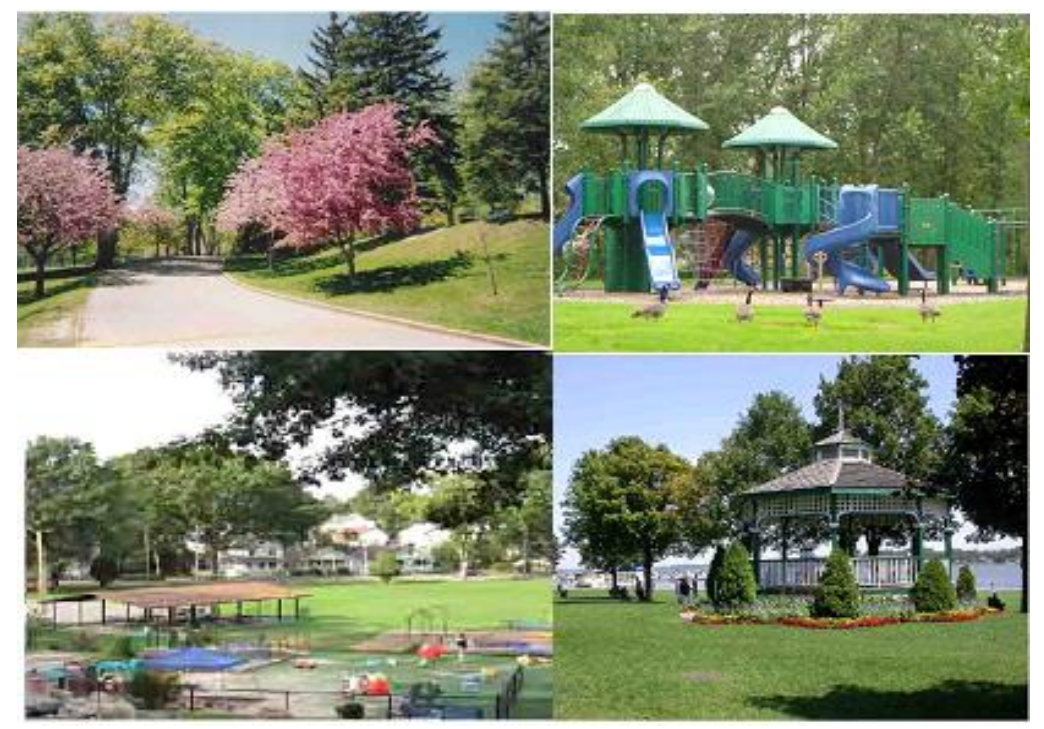


Examples of this type of park include Birkenhead Park in England, designed by Sir Joseph Paxton; Jean Charles Alphand's Bois de Boulogne, outside Paris; Central Park in New York City, designed by Frederick Law Olmsted and Calvert Vaux; the Botanic Gardens in Melbourne, Australia; and Akashi Park in Kōbe, Japan. The design was generally romantic in character. The primary purpose was to provide for passive recreation-walking and taking the air in agreeable surroundings reminiscent of the unspoiled country.

What primarily differentiates modern parks is their accommodation for active recreation. Park areas differ considerably from country to country, and their designs reflect differences in climate, cultural attitudes, social habits, and pastimes. In the gardens of the Generalife, a Spanish family may enjoy its holiday outing in a shaded bosque near a cool fountain. On an evening in Venice, a procession with banners and torches may sweep into one of the little piazzas. In the ButtesChaumont in Paris, children may reach out from wooden horses on the merry-goround to seize a brass ring. During the bright summer weekends in Stockholm, residents cultivate vegetables in allotment gardens that are leased to them by the park department. In Israel, Iran, and Pakistan, basketball, football (soccer), and kabadei (a game like rugby) are played in parks; in Japan, volleyball, tennis, and sumo (wrestling) may be seen. Almost universally, there is recognition of the creative possibilities of leisure and of community responsibility to provide space and facilities for recreation. The facilities include outdoor theatres, zoos, concert shells, historical exhibits, concessions for dining and dancing, amusement areas, boating, and areas for sports of all kinds, such as fly-casting pools and skating rinks.
There is always the danger that the original reason for creating the park-i.e., to bring a part of nature within reach of the city dweller-will be sacrificed to its specific recreational functions. It is difficult to keep the balance, because the tempo of urban life has mounted and with it the requirements for intensive use. Another danger to the public park is the automobile. With the tremendous growth in automobile traffic and, consequently, increasing pressure from traffic authorities for more land, there has been hardly a major city that has not lost sections of its parks to highways. There has been a growing awareness, particularly in Europe, that large-scale urban planning should be carried out in such a way that traffic functions are clearly separate and do not encroach on other spheres. In the United States, there have been victories for the park user against the automobile; in San Francisco, the state freeway was halted at the city limits, and, in New York City, Washington Square was closed to traffic.

It is unfortunate that the word park has come to connote almost exclusively the "romantic" style park or English garden of the 19th century. In truth, there are other traditions whose influence has been equally vital. How different from the Parisian Buttes-Chaumont, for instance, are the Tuileries across the river. These were laid out under the supervision of Marie de Médicis in the style of the Boboli Gardens in Florence. Also the parks of Versailles, the Belvedere Park in Vienna, the Vatican Gardens in Rome, Hellbrun in Salzburg, Blenheim in England, Drottning sholm in Sweden and Peterhof (Petrodvorets) in Russia are all parks that were planned in the Italian Baroque tradition. They were intended not to be a foil or escape from the oppressive city but rather to be its central dramatic focus-a 
display for the opulence of rulers, a piazza for the moving of great crowds, from the tournament and guild ceremonies of Florence in the 17th century to the formal pageantry of the court. It was in the Baroque park that the handling, control, and stimulation of crowds in the open air developed as one of the great arts of the urban designer. Another park tradition that has had worldwide influence is that of Islam.

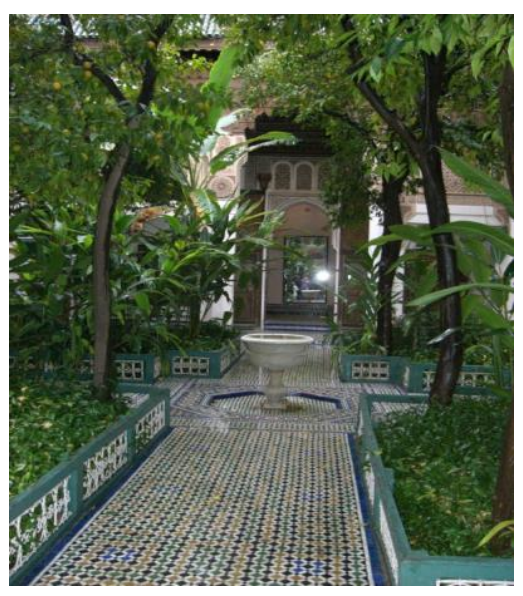

In Tehran, Marrakech, Sevilla (Seville)

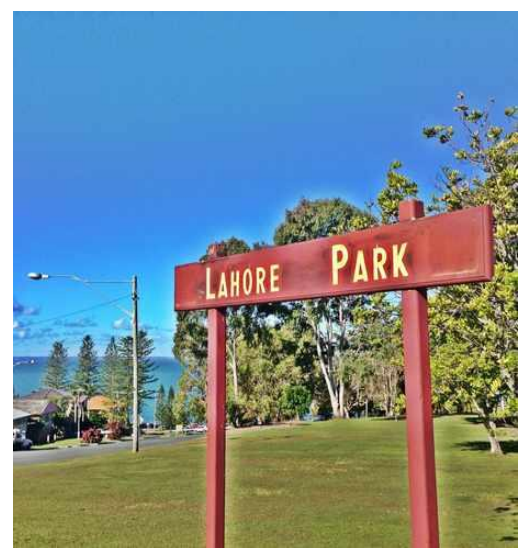

Lahore

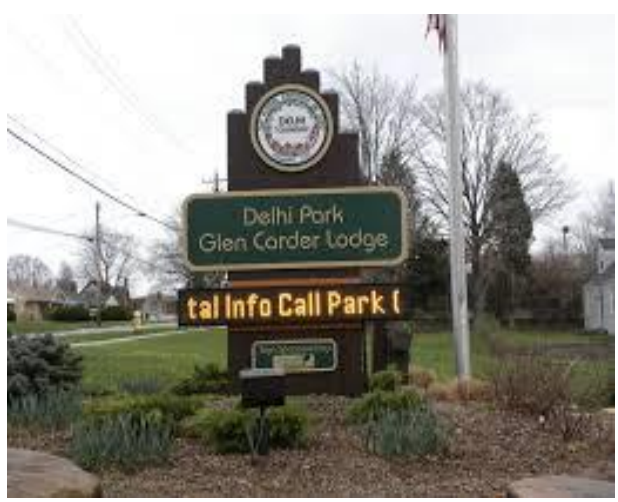

Delhi 
This tradition is the dominant one and, as with all parks, developed according to the climate, social custom and religious ethos. The original Muslim idea was to think of the garden as a paradise, a symbol of the afterlife as an oasis of beauty blooming in the earthly desert. Water and the cypress are the two main elements. Within the park, then, are water, the symbol of purity, in the four-way river of paradise, and trees (above all the cypress, symbolizing life), surrounded by high walls to keep out the dry wind. Everywhere, in keeping with Muslim belief, the design pattern is abstract rather than figurative. The fundamental idea creates its own specific technical skills; nowhere is there more artful use of irrigation for plants, of jets of water to cool the air, of orchards for shade, of color to break up the sun's glare, or of the use of masonry patterns than in these Islamic gardens. The Taj Mahal in India dates from the 17th century, when by the testament of Shah Jahan this area of 20 acres (8 hectares) was to be maintained as a public grounds in perpetuity, where the poor could walk and pick fruit. In China and Japan, a similar opening of the royal precinct for public enjoyment, as with the Winter Palace or the Katsura Imperial Villa Gardens in Kyōto, has been a more recent development. The great religious shrines, however, have always resembled Western parks. The Horimonji temple in Tokyo, the Mimeguri shrine, the great Buddhist temple at Ise, and the Inner (Shintō) shrine at Mieshima are examples of an age-old garden tradition in which humanity is but "one of a thousand things" and where nature is presented in an idealized and symbolic way as an object for contemplation and spiritual enjoyment. In their techniques of horticulture and in their use of stones, water, and surface textures, the gardens of East Asia are of a high level. This Eastern tradition had its effect on European park design in the 18th century and again in the 20th century, as in the grounds for the UNESCO building in Paris, designed by Isamu Noguchi. Research questions Vital effect of parks regarding air pollution and psychological in balances on our contemporary life? Abstract. Urban forests in the coterminous United States are estimated to produce «61 million metric tons (67 million tons) of oxygen annually, enough oxygen to offset the annual oxygen consumption of approximately two-thirds of the U.S. population. Although oxygen production is often cited as a significant benefit of trees, this benefit is relatively insignificant and of negligible value as a result of the large oxygen content of the atmosphere. Other benefits of the urban forest are more critical to environmental quality and human health than oxygen production by urban trees. Air quality; environmental quail Urban vegetation, particularly trees, provides numerous benefits that can improve environmental quality and human health in and around urban areas. These benefits include improvements in air and water quality, building energy conservation, cooler air temperatures, reductions in ultraviolet radiation, and many other environmental and social benefits (Nowak and Dwyer 2007). Although many ecology textbooks reveal that the vast majority of oxygen-producing organisms in the world are aquatic, oxygen production is one of the most commonly cited benefits of urban trees. Common questions related to the benefits of urban forests are directed toward understanding the amount of oxygen produced by urban forests, often in relation to the amount of oxygen consumed by humans. It is well known that trees produce oxygen, but how significant is the oxygen production benefit provided by urban forests? The 
purpose of this article is to estimate the oxygen production by urban forests in select cities and nationally, compare it with estimated oxygen consumption by the U.S. population, illustrate why oxygen production by urban trees is a relatively unimportant benefit, and compare this benefit with other environmental benefits provided by urban trees and forests.

\section{Methodology}

\section{Field Data}

Randomly located 0.04 ha $(0.1$ ac) field plots were measured in 16 cities to sample the entire urban forest structure of that city (e.g., tree species composition, number of trees on all land uses) (Table 1). These cities were sampled in collaboration with a number of cooperators, all of whom used methods developed by the USDA Forest Service for various urban forest research projects (e.g., Nowak and Crane 2000; Nowak et al. 2005). Data collection included land use, tree species, and stem

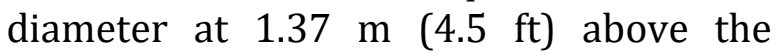
ground (dbh), tree and crown heights, crown width, and canopy condition. Oxygen Production by Trees oxygen production by trees is based on the amount of oxygen produced during photosynthesis minus the amount of oxygen consumed during plant respiration (Salisbury and Ross 1978): Photosynthesis: «(CO2) + «(H2O) + light $>(\mathrm{CH} 2 \mathrm{O}),+$ + «O2 Respiration: (CH2O), + $« 02-n(\mathrm{CO} 2)+\mathrm{n}(\mathrm{H} 2 \mathrm{O})+$ energy If carbon dioxide uptake during photosynthesis exceeds carbon dioxide release by respiration during the year, the tree will accumulate carbon (carbon sequestration). Thus, a tree that has a net accumulation of carbon during a year (tree growth) also has a net production of oxygen. The amount of oxygen produced is estimated from carbon sequestration based on atomic weights: net 02 release $(\mathrm{kg} / \mathrm{yr})=$ net $\mathrm{C}$ sequestration $(\mathrm{kg} / \mathrm{yr}) \mathrm{x}$ $32 / 12$.

Client in cyberspace like any other buyer is provided with Warranty against hidden defects and Warranty understanding, where this, in Iran law, is defined in the implied terms. Such guarantees are relatively associated to being committed to provide information, because if the seller does not be the owner of a property intending to sell it, so the seller is committed to the truth to the purchaser; otherwise, warranty of understanding as mentioned in article 391 of civil law has to pay fined for the damaged received by consumer. The conditions for acting Warranty against hidden defects in online sale with the conditions extracted by traditional legal procedures to sell that good in a real environment would not be different (Dablephon, Zarkalam, 2012). One of the types of defects is the defect caused by failure to disclose information. Goods, due to a failure to provide necessary and appropriate information about the risks and potential losses and how to exploit it may be considered defective. Thus violating the obligation to provide information not only creates liability for the supplier, but also causes goods sold to be considered defective. Non-disclosure of information in cases mentioned above reduces abuse and exploitation of it- and this leads to a deterioration of the sales (Salehi, Ebrahimi, Salari Rad, 2012). Mazo believes that the seller has to provide the good for the purchaser to use it, and then he has to provide the purchaser with the necessary information to use the object sold (Joneidi, 2002).

\section{Tree}

\section{Biomass}


The net amount of oxygen produced by a tree during a year is directly related to the amount of carbon sequestered by the tree, which is tied to the accumulation of tree biomass. Biomass for each measured tree was calculated using equations from the literature with inputs of $\mathrm{dbh}$ and tree height (see Nowak 1994; Nowak et al., 2002a). Equations that predict aboveground biomass were converted to whole tree biomass based on a belowground to aboveground ratio of 0.26 (Cairns et al., 1997). Equations that compute fresh weight biomass were multiplied by species- or genus-specific conversion factor tors to yield dry weight biomass. These conversion factors, derived from average moisture contents of species given in the literature, averaged 0.48 for conifers and 0.56 for hardwoods (Nowak 1994). Open-grown, maintained trees tend to have less above-ground biomass than predicted by forest-derived biomass equations for trees of the same diameter at breast height (Nowak 1994). To adjust for this difference, biomass results for opengrown urban trees were multiplied by a factor of 0.8 (Nowak 1994). No adjustment was made for trees found in more natural stand conditions (e.g., vacant lands, forest preserves). Because deciduous trees drop their leaves annually, only carbon stored in woody biomass was calculated for these trees. Total tree dry weight biomass (above- and below-ground) was converted to total stored carbon by multiplying by 0.5 .

Multiple equations developed for a single tree species were combined to produce one predictive equation for a wide range of diameters for each species. The process of combining the individual formulas (each with limited diameter ranges) into one more general species formula produced results that were typically within $2 \%$ of the original estimates for total carbon storage of the urban forest (i.e., the estimates using the multiple equations). Formulas were combined to prevent disjointed sequestration estimates that can occur when calculations switch between individual biomass equations. If no biomass equation could be found for an individual species, the average of results from equations of the same genus was used. If no equations for the genus were found, the average of results from all broadleaf or conifer equations was used. Standard errors given for carbon report sampling error rather than error of estimation. Estimation error is unknown and likely larger than the reported sampling error. Estimation error also includes the uncertainty of using biomass equations and conversion factors, which may be large, as well as measurement error, which is typically small. Urban Tree Growth and Carbon Sequestration

Average diameter growth from the appropriate land use and diameter class was added to the existing tree diameter (year $\mathrm{x}$ ) to estimate tree diameter in year $\mathrm{x}$ +1 . For urban trees in forest stands, average dbh growth was estimated as 0.38 $\mathrm{cm} /$ year (0.15 in/year) (Smith and Shifley 1984); for trees on land uses with a parklike structure (e.g., parks, cemeteries, golf courses), average dbh growth was 0.61 $\mathrm{cm} /$ year (0.24 in/year) (deVries 1987); for more open-grown trees, dbh class-specific growth rates were based on Nowak (1994). Average height growth was calculated based on formulas from Fleming (1988) and the specific dbh growth factor used for the tree. Growth rates were adjusted based on tree canopy condition. Adjustment factors were proportional to percent crown dieback (i.e., the greater the crown dieback, the slower the growth rate) and the 
assumption that less than 25\% crown dieback had a limited effect on dbh growth rates. For trees with fair to excellent condition (less than 25\% dieback), no adjustment was made to the growth rate; for poor condition trees (26\% to 50\% dieback), growth rates were multiplied by 0.76; critical trees (51\% to $75 \%$ dieback) by 0.42 ; dying trees ( $76 \%$ to $99 \%$ dieback) by 0.15 ; and dead trees by 0 . The difference in estimates of carbon storage between year $\mathrm{x}$ and year $\mathrm{x}+1$ is the net amount of carbon sequestered annually. Tree death leads to the eventual release of stored carbon. To estimate the net amount of carbon sequestered by the urban trees after decomposition, carbon emissions resulting from decomposition after tree death must be considered. To calculate the potential release of carbon resulting from tree death and decomposition, estimates of annual mortality rates by condition class were derived from a study of street-tree mortality (Nowak 1986). Annual mortality was estimated as $1.9 \%$ for trees 0 to 3 in $\mathrm{dbh}$ in the good-excellent condition class (less than $10 \%$ dieback); $1.5 \%$ for trees greater than 3 in $\mathrm{dbh}$ in the good-excellent condition class; $3.3 \%$ for trees in fair condition ( $11 \%$ to $25 \%$ dieback); $8.9 \%$ for poor condition; $13.1 \%$ for critical condition; 50\% for dying; and 100\% for dead. Two types of decomposition rates were used: 1) rapid release for aboveground biomass of trees that are projected to be removed and 2) delayed release for standing dead trees and tree roots of removed trees. Trees that are removed from urban sites are not normally developed into wood products that provide for long-term carbon storage (i.e., removed trees are often burned or mulched); therefore, they will most likely release their carbon relatively soon after removal. If dead trees are not removed annually, they have an increased probability of being measured in the tree sample, and decomposition rates must reflect this difference. All trees on vacant, transportation, and agriculture land uses, and $50 \%$ of trees in parks, were assumed to be left standing (i.e., not removed) because these trees are likely within forest stands and/or away from intensively maintained sites. These trees were assumed to decompose over a period of 20 years. Data on tree decomposition rates are limited. However, using decomposition rates from 10 to 50 years had little effect on overall net decomposition within a single year. Trees on all other land uses were assumed to be removed within 1 year of tree death. For removed trees, aboveground biomass was assumed to be mulched with a decomposition rate of 3 years; below-ground biomass was assumed to decompose in 20 years. Although no mulch decomposition studies could be found, studies on decomposition reveal that $37 \%$ to $56 \%$ of carbon in tree roots and $48 \%$ to $67 \%$ of carbon in twigs is released within the first 3 years (Scheu and Schauermann 1994). Estimates of carbon emissions resulting from decomposition were based on the probability of the tree dying within the next year and the probability of the tree being removed using the formula:

Emission = C X Mc XXpi $(($ Dremove $)+$
$($ Dstand $))$ Dremove $=($ pab $/$ yi $)(1 / \mathrm{dm})+$
$\begin{aligned} & +(1-\mathrm{pab}) / \mathrm{yi})(1 / \mathrm{dr}) \\ & 1) / \mathrm{yi})(1 / \mathrm{dr})\end{aligned}$

where emission $=$ individual tree contribution to carbon emissions; $\mathrm{C}=$ carbon storage in the next year; $\mathrm{Mc}=$ probability of mortality based on condition class; $\mathrm{i}=$ decomposition class (based on number of years left standing before removal); pi = proportion of the land use tree population in decomposition class i; 
pab $=$ proportion of tree biomass aboveground; yi = number of years left standing before removal (yi — ${ }^{\circ}$ for dead trees that will never be cut down (natural decomposition)); $\mathrm{dm}=$ decomposition rates for mulched aboveground biomass ( 3 years); and $\mathrm{dr}=$ decomposition rate for standing trees and tree roots (20 years). Individual tree estimates of mortality probability and decomposition rates were aggregated upward to yield total estimates of decomposition for the tree population. The amount of carbon sequestered as a result of tree growth was reduced by the amount lost resulting from tree mortality to estimate a net carbon sequestration rate that accounts for carbon loss resulting from decomposition.

\section{Human Oxygen Consumption}

An average adult human oxygen consumption rate of $0.84 \mathrm{~kg} /$ day (1.85 lb/day) (Perry and LeVan c. 2003) was used to estimate how much human oxygen consumption would be offset by urban forest oxygen production annually. To estimate how much human oxygen consumption would be offset, oxygen production was divided by average annual oxygen consumption per person.

\section{Results}

Net annual oxygen production by urban forests (after accounting for decomposition) in selected cities ranged from 1,000 metric tons (1,100 tons) in Freehold, New Jersey, U.S. to 86,000 metric tons $(94,800$ tons) in Atlanta, Georgia (Table 2). This net oxygen production offsets oxygen consumption from between $2 \%$ of the human population in Jersey City, New Jersey, and New York, New York, to greater than $100 \%$ in Moorestown, New Jersey. Mean net annual oxygen production (after accounting for decomposition) per hectare of trees
(100\% tree canopy) offsets oxygen consumption of 19 people per year (eight people per acre of tree cover), but ranges from nine people per hectare of canopy cover (four people/ac cover) in Minneapolis, Minnesota, to 28 people/ha cover (12 people/ac cover) in Calgary, Alberta. The average number of trees needed to offset the annual oxygen consumption of one adult was 30 trees (net oxygen production after accounting for decomposition) but ranged from 17 trees in Freehold, New Jersey, to 81 trees in Calgary, Alberta. This difference is a reflection of different tree sizes, conditions, and growth rates among these cities. Tree oxygen production varies by tree size. Based on data from Minneapolis, Minnesota (Nowak et al. 2006b), trees 1-3" $\mathrm{dbh}$ produced «2.9 $\mathrm{kg} 02 /$ year $(6.4 \mathrm{lb}$ 02/year); trees 9-12" dbh: $22.6 \mathrm{~kg}$ 02/year (49.9 lb 02/year); 18-21" dbh: $45.6 \mathrm{~kg} \mathrm{02/year} \mathrm{(100.5} \mathrm{lb} \mathrm{02/year);} 27$ 30" dbh: $91.1 \mathrm{~kg}$ 02/year (200.8 lb 02/year); and greater than 30" dbh: 110.3 kg 02/year (243.2 lb 02/year).

Based on the national estimate of net carbon sequestration in the coterminous United States of 22.8 million metric tons $\mathrm{C} /$ year (25.1 million tons C/year) (Nowak and Crane 2002), urban forests in the United States produce «61 million metric tons (67 million tons) of oxygen annually, which is enough oxygen to offset human oxygen consumption for approximately two-thirds of the U.S. population.

\section{Discussion}

Oxygen production by trees varies among cities based on differences in number of healthy trees, growth rates, and diameter distributions. Cities with mostly small trees would require more trees on average to offset the oxygen consumption of one person. Percent of the population's oxygen consumption offset by urban forests varies 
depending on population density and total oxygen production. Cities with high human population density (e.g., Jersey City and New York) tend to have the lowest proportion of their oxygen consumption offset by their urban forest. A commonly cited statement zAnnual oxygen production by the urban forest (thousands of metric tons per year). Multiply by 1.102 to convert to tons. yNumber of people and percent of city population that urban forest oxygen production offsets in terms of average adult human oxygen consumption per year. "Average number of people whose oxygen consumption is offset by oxygen production per hectare of tree cover in the city (no./ha; divide by 2.471 to convert to no./ac) and average number of trees needed in city to offset the oxygen consumption of one adult human (no. of trees). Net $=$ net oxygen production of population without consideration of decomposition; Net $\mathrm{w} / \mathrm{d}=$ net oxygen production of population considering decomposition; net production minus estimated oxygen consumed resulting from decomposition; $\mathrm{SE}=$ standard error. Provide enough oxygen for 18 people (e.g., American Forests 2006; Tree-People 2006), but based on this study, this estimate appears to be high by at least a factor of two. The number is more on the order of eight people per acre of tree cover (100\% tree canopy). Oxygen production per acre of tree cover will vary based on tree density, diameter distribution, and tree health and growth.

Oxygen production is one of many environmental benefits that trees produce, and urban trees can produce a significant amount of oxygen. However, is this oxygen production actually creating a significant environmental benefit in comparison with other environmental benefits of trees such as carbon sequestration and air pollution removal? In the coterminous United States, annual carbon sequestration by urban forests is estimated at 22.8 million metric tons (25.1 million tons) with a societal value of $=\$ 460$ million per year (Nowak and Crane 2002). Air pollution removal in the coterminous United States is estimated at 711,000 metric tons (784,000 tons) with a $\$ 3.8$ billion annual value (Nowak et al. 2006a). Oxygen production by U.S. urban forests is estimated at 61 million metric tons (67 million tons), but the value to society is negligible. The reason the oxygen production value of urban trees is insignificant has to do with the large amount of oxygen within the atmosphere (approximately 21\% of the atmosphere's volume is oxygen). As stated by Miller (1979): "We have a large number of serious ecological problems, but suffocation from lack of oxygen is not one of them (Broecker 1970; SCEP 1970). The oxygen content of the atmosphere remains essentially constant with the oxygen consumed by all animals, bacteria, and respiration processes roughly balanced by the oxygen released by land and sea plants during photosynthesis. The present atmospheric oxygen content seems not to have changed since 1910 (SCEP 1970). Furthermore, because air is about 20 percent oxygen, the total supply is immense (Broecker 1970)." Our atmosphere has such an enormous reserve of oxygen that even if all fossil fuel reserves, all trees, and all organic matter in soils were burned, atmospheric oxygen would only drop a few percent (Broecker 1996). Also, waters of the world are the main oxygen generators of the biosphere; their algae are estimated to replace $=90 \%$ of all oxygen used (Encyclopedia Britannica 1994). Thus, although urban trees do produce significant amounts of oxygen, it is not a significant ecologic benefit given the global nature of oxygen 
and the sheer volume of oxygen in the atmosphere.

A growing forest will remove carbon dioxide and produce oxygen. Conversely, a decaying or declining forest will release carbon dioxide and consume oxygen through decomposition processes. If forest canopy cover is increased (more trees are added) and sustained through time, net carbon dioxide will be removed and oxygen produced. Given the carbon dioxide level in the atmosphere ( $\ll 0.03 \%)$ is much less than the oxygen level (21\%), the relative impact of urban forests and their management are much more significant for carbon dioxide than for oxygen. Fossil fuel combustion also consumes oxygen and as a result of fossil fuel use, the oxygen content of the atmosphere is slowly declining. Between 1989 and 1994, the oxygen content of the atmosphere dropped at an annual rate of 2 ppm out of 210,000 ppm (Broecker 1996). Thus, reducing fossil fuel use in the management of urban forests not only reduces emission of carbon dioxide, but also the consumption of oxygen. If fossil fuels are consistently used to maintain an urban forest, the net effect of the forest and its management will be carbon dioxide production and oxygen consumption. The point in the future when carbon emissions from maintenance exceed carbon sequestration by the forest varies by tree species and intensity of fossil fuel-based management (Nowak etal. 2002b). Urban trees can improve air quality (e.g., Cardelino and Chameides 1990; Taha 1996; Nowak et al. 2000, 2006a). Because small changes in air pollution concentrations can have relatively considerable impacts on air quality and human health, the effects of urban forests on air pollution can be significant. Recently, the U.S. Environmental Protection Agency has introduced urban tree cover as a potential emerging measure to help meet air quality standards (U.S. Environmental Protection Agency 2004; Nowak 2005). In general, tree effects on trace chemicals in the atmosphere (chemicals that are minor components of the total atmosphere) will have a much greater relative impact on environmental quality and human health than chemicals such as oxygen that comprise a large proportion of the atmosphere. Relatively minor changes in trace chemicals can have significant effects on environmental and human health (e.g., impacts of ozone, particulate matter, nitrogen, and sulfur oxides) and climate change (e.g., impact of carbon dioxide). Although the absolute magnitude of oxygen production by urban forests is over 2.5 times greater than for carbon sequestration and 85 times greater than for air pollution removal nationally, the relative impacts of carbon sequestration and air pollution removal are much more significant than oxygen production. Urban forest effects on trace chemicals can lead to significant improvements in environmental quality and human health and well-being. Data analysis is an acre of trees (100\% tree canopy).

\section{Conclusion}

Urban forests produce large amounts of oxygen. However, with the large and relatively stable amount of oxygen in the atmosphere and extensive production by aquatic systems, this tree benefit is relatively insignificant. Tree impacts on important atmospheric trace chemicals such as carbon dioxide and U.S. Environmental Protection Agency criteria air pollutants (ozone, particulate matter, sulfur dioxide, nitrogen dioxide, carbon monoxide, and lead) will have greater significant impacts on human health and

89 | Page 
environmental quality. Urban forest carbon sequestration and air pollution removal along with other environmental impacts of urban forests (e.g., water quality improvement, lower air temperatures, reduced ultraviolet radiation loads) need to be better incorporated within local and regional planning efforts to improve environmental quality and enhance the quality of urban life.

\section{Acknowledgments}

This work was funded, in part, by the USDA Forest Service, RPA Assessment Staff, and State and Private Forestry, Cooperative Forestry's Urban and Community Forestry Program. Data collection in Baltimore, funded by the USDA Forest Service, is part of the National Science Foundation's Long-Term Ecosystem Research project. Data from cities in New Jersey were collected and analyzed in cooperation with Mike D' Errico and the State of New Jersey, Department of Environmental Protection and Energy, Division of Parks and Forestry; Calgary data collection was by Simon Wilkins, City of Calgary; Minneapolis data collection was by Davey

How to cite this article: Farzad Zarbakhsh, Jafar Yousefpour, Younes Karimpour Hayedi, Farhad Yadegari, Public Park. International Journal of Advanced Studies in Humanities and Social Science, 2019, 8(1), 78-90. http://www.ijashssjournal.com/article 84111.html
Resource Group; San Francisco data collection was by Alexis Harte and the City of San Francisco; Toronto data collection was by Andy Kenney and the University of Toronto; Washington, DC, data collection was by Casey Trees Endowment Fund and the National Park Service; Morgantown data collection was by Jonathan Cumming and Sandhya Mohan (University of West Virginia); and Atlanta, Georgia, Boston, Massachusetts, New York, New York, and Philadelphia, Pennsylvania, data were collected by ACRT, Inc.

\section{References}

Foran, C. (2013). How to Design a City for Women, The Atlantic Cities.

Salford City Council: Parks in Broughton and Blackfriars Retrieved on 2008-09-03

Papillon Graphics' Virtual Encyclopaedia of Greater Manchester: The Campaign for City Parks in Manchester and Salford Retrieved on 2008-09-06

University of Salford: Peel Park Retrieved on 2008-09-07 